\title{
Unilateral Giant Bullae: Pulmonary Placental Transmogrification Should Be Kept in Mind: Case Reports
}

\author{
Abdel-Mohsen M. Hamad, M.D. ', Mona M. Nosseir, M.D. ', Saleh M. Alorainy, M.D. \\ Departments of ${ }^{1}$ Thoracic Surgery and ${ }^{2}$ Pathology, King Fahd Specialist Hospital, Buraydah, Saudi Arabia
}

\section{ARTICLE INFO}

Received October 8, 2020

Revised November 11, 2020

Accepted November 29, 2020

Corresponding author

Abdel-Mohsen M. Hamad

Tel 966-565618155

Fax 966-565618155

E-mail mohn_hammad@yahoo.com

ORCID

https://orcid.org/0000-0003-1303-0818

\begin{abstract}
Placental transmogrification is a peculiar clinical entity of the lung of uncertain etiology. We report 2 cases of pulmonary placental transmogrification in 2 patients of different nationalities. Both of them had no history of smoking or chronic lung disease. The main presentations were dyspnea and chest pain. Radiologic studies showed a unilateral giant bulla in both patients; additional pneumothorax was present in only 1 patient. They underwent surgical bullectomy. Histopathologic studies revealed the presence of intracystic placenta-like villous structures and a diagnosis of placental transmogrification was made. Placental transmogrification should be considered in cases of unilateral bullae.
\end{abstract}

Keywords: Emphysema, Bullae, Placenta, Case report

\section{Case report}

We present 2 cases of placental transmogrification (PT) of the lung. Data were collected from patients' files; the study was approved by the hospital review committee.

\section{Case 1}

A 25-year-old non-smoking African woman with no history of previous chest troubles presented with acute-onset chest pain and shortness of breath. Chest radiography gave the impression of loculated pneumothorax. Computed tomography (CT) of the chest verified the presence of rightside pneumothorax, with a large bulla in the right lower lobe (Fig. 1A) and multiple variably-sized bullae involving most of the outer surface of the upper lobe. A chest drain was inserted and on a later date the patient underwent surgical resection of the lower lobe bulla (Fig. 1B) and electrocautery ablation of the upper lobe bullae, in addition to mechanical pleural abrasions. We started with video-assisted thoracoscopic surgery (VATS) and then converted to small muscle-sparing lateral thoracotomy with the assistance of a thoracoscopic camera due to marked adhesions of the upper lobe. At her last visit, she was doing well 1 year after surgery.

\section{Case 2}

A 28-year-old Jordanian woman presented with rightside vague chest pain and shortness of breath of 2 weeks'
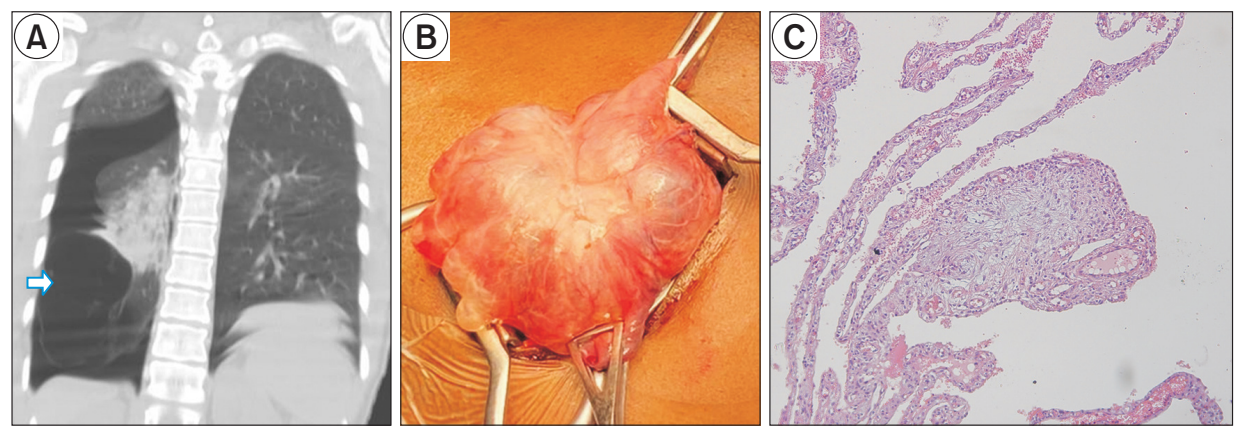

Fig. 1. (A) Coronal view of chest computed tomography showing the presence of a double air line (white arrow), denoting the presence of pneumothorax and lower lobe bulla. (B) The bulla was extracted through the incision before resection. (C) Histopathologic examination showing intracystic placenta-like villous lesions (H\&E stain, $\times 4)$.

Copyright (C) 2021, The Korean Society for Thoracic and Cardiovascular Surgery

(i) (\$) This is an Open Access article distributed under the terms of the Creative Commons Attribution Non-Commercial License (http://creativecommons.org/licenses/ by-nc/4.0) which permits unrestricted non-commercial use, distribution, and reproduction in any medium, provided the original work is properly cited. 

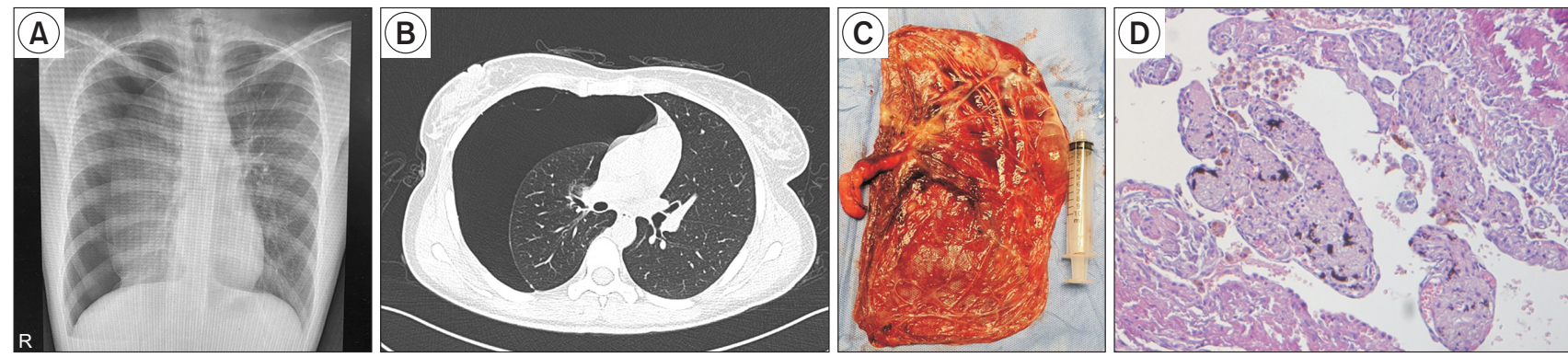

Fig. 2. (A) Chest X-ray showing a right-side radiolucency simulating pneumothorax. (B) Chest computed tomography (axial view), showing a giant bulla with some trabeculae. (C) Gross photography of the resected giant lung bulla. (D) Histopathologic study showing intracystic papillary lesions $(\mathrm{H} \& \mathrm{E}$ stain, $\times 4)$.

duration. She was non-smoker and had no history of chronic lung diseases. At the time of presentation, she had an average body build and her vital signs and oxygen saturation were within normal ranges. The chest X-ray was initially interpreted as showing right-side pneumothorax, but $\mathrm{CT}$ of the chest enabled a diagnosis of right-side giant bulla with a compression effect on the lung and shift of the mediastinum (Fig. 2A, B). The patient underwent right-side VATS bullectomy (Fig. 2C) and mechanical pleural abrasions. She was doing well 8 months after surgery.

Histopathologic examinations of the resected bullae of both patients showed intracystic proliferation of papillary structures; the papillary cores contained congested blood vessels and were surrounded by hyperplastic alveolar pneumocytes. Therefore, a diagnosis of PT of the lung was made (Figs. 1C, 2D).

This study was conducted in accordance with the amended declaration of Helsinki and the approval of our institutional review board. Both patients provided written informed consent for publication of their clinical details and images.

\section{Discussion}

Bullous emphysema is a form of emphysema characterized by the presence of bullae. The main predisposing factors for its occurrence are tobacco smoking and $\alpha_{1}$-antitrypsin deficiency. In advanced cases, the pathologic process is usually diffuse and affects both lungs. However, bullae may occur in lungs that are otherwise normal [1].

Unilateral bullae occupying most of the hemithorax are seldom seen. In 1979, McChesney [2] described a rare congenital form of giant bullous emphysema; he coined the term "pulmonary placental transmogrification" because of the morphological resemblance of the intracystic papillary or villous structures to immature placental chorionic villi.
However, in fact, PT has no biological or biochemical relationship to the placenta [2].

Fewer than 40 cases of PT have been reported in the English-language literature. The condition is most common in middle-aged men. In this report, we presented 2 female cases of different nationalities diagnosed within a period of 1 year. Our center serves a multinational community, which may explain this unusual presentation. However, some issues about the actual prevalence of the condition should be raised. It is possible that the diagnosis is missed or ignored in some cases. Furthermore, reluctancy to publish new cases could be another cause of the low reported prevalence of the condition. We encourage good communication between the surgeon and the pathologist when the clinical diagnosis of PT is suspected.

In his first report, McChesney [2] considered PT as an unrecognized hamartoma. Even more than 40 years after that report, the exact etiology of PT remains controversial. In view of the frequent occurrence of PT with emphysema, some authors consider it as a variant or a complication of bullous emphysema [3]. However, Xu et al. [4] confirmed the presence of PT in 6 cases of pulmonary fibrochondromatous hamartoma, and argued that PT is a hamartomatous lesion. On the contrary, Cavazza et al. [5], using immunohistochemical, ultrastructural, and molecular studies, identified genotypic alterations in the clear cell component of PT, but not in the adjacent normal tissue; accordingly, they attributed PT to benign proliferation of immature interstitial "clear cells" with secondary cystic changes, rather than being a variant of emphysema. Another proposal was introduced by Yang et al. [6], who reported PT in a newly developed pulmonary nodule and therefore considered PT to be a pattern of benign morphological changes that may be encountered in both congenital and acquired lesions, rather than being an independent disease. In view of these conflicting reports, we consider 
that the pathogenesis of PT and its clinical implications require further study. Collection of available data on all reported cases and the pathological materials to be analyzed in detailed studies at a single center may reveal important information.

Clinically, PT is more common in middle-aged men than in other demographic categories. The reported cases were either asymptomatic or presented with dyspnea, chest pain, pneumothorax (possibly tension pneumothorax), hemoptysis, or a combination of all of the above. In 1 case, the condition was present in association with lung cancer $[7,8]$. Radiologic studies showed unilateral bullous lesions, cystic changes with or without an associated mass, or non-solid lung nodules containing several small round air spaces [9].

In some cases, like our second case, the differentiation between giant bulla and pneumothorax on chest radiography can be difficult; in this situation, chest CT is useful and provides important assistance for the diagnosis. Waitches et al. [10] suggested that the presence of air outlining both sides of the bulla wall that is parallel to the chest wall is a clue for the diagnosis of the simultaneous presence of both pneumothorax and bulla; they called this the "double-wall sign." The absence of the double-wall sign provides confidence for ruling out the diagnosis of pneumothorax. One should be careful when 2 large bullae are adjacent to one another, producing an apparent double-wall sign; in this situation, the bulla wall will not be parallel to the chest wall [10].

The criteria for surgical resection of bullae are generally determined by degree of dyspnea. However, resection is also advised for asymptomatic patients with bullae occupying more than one-third of the hemithorax to avoid potential complications. During surgery, resection of the pathologic lesion with preservation of healthy lung tissue is recommended.

In summary, PT should be considered in the diagnosis of patients with large unilateral bullae without traditional risk factors for emphysema. The pathogenesis of PT and its clinical and pathological implications are still in need of further research.

\section{Conflict of interest}

No potential conflict of interest relevant to this article was reported.

\section{Acknowledgments}

We would like to express our grateful appreciation to
Prof. Ahmed Elmahrouk, professor of cardiothoracic surgery, for reviewing and editing the English language of the manuscript. We would also like to thank Dr. Anas Alkhalifa, registrar of thoracic surgery, for his assistance in collecting the data.

\section{ORCID}

Abdel-Mohsen M. Hamad: https://orcid.org/0000-0003-1303-0818

Mona M. Nosseir: https://orcid.org/0000-0003-4658-0234

Saleh M. Alorainy: https://orcid.org/0000-0002-0400-0863

\section{References}

1. Morgan MD, Edwards CW, Morris J, Matthews HR. Origin and behaviour of emphysematous bullae. Thorax 1989;44:533-8.

2. McChesney T. Placental transmogrification of the lung: a unique case with remarkable histopathologic features. Lab Invest 1979;40: 245-6.

3. Fidler ME, Koomen M, Sebek B, Greco MA, Rizk CC, Askin FB. Placental transmogrification of the lung, a histologic variant of giant bullous emphysema: clinicopathological study of three further cases. Am J Surg Pathol 1995;19:563-70.

4. Xu R, Murray M, Jagirdar J, Delgado Y, Melamed J. Placental transmogrification of the lung is a histologic pattern frequently associated with pulmonary fibrochondromatous hamartoma. Arch Pathol Lab Med 2002;126:562-6.

5. Cavazza A, Lantuejoul S, Sartori G, et al. Placental transmogrification of the lung: clinicopathologic, immunohistochemical and molecular study of two cases, with particular emphasis on the interstitial clear cells. Hum Pathol 2004;35:517-21.

6. Yang M, Zhang XT, Liu XF, Lin XY. Placental transmogrification of the lung presenting as a peripheral solitary nodule in a male with the history of trauma: a case report. Medicine (Baltimore) 2018;97: $\mathrm{e} 0661$.

7. Dunning K, Chen S, Aksade A, Boonswang A, Dorman S. Placental transmogrification of the lung presenting as tension pneumothorax: case report with review of literature. J Thorac Cardiovasc Surg 2008; 136:778-80.

8. Hamza A, Khawar S, Khurram MS, et al. Pulmonary placental transmogrification associated with adenocarcinoma of the lung: a case report with a comprehensive review of the literature. Autops Case Rep 2017;7:44-9.

9. Shapiro M, Vidal C, Lipskar AM, Gil J, Litle VR. Placental transmogrification of the lung presenting as emphysema and a lung mass. Ann Thorac Surg 2009;87:615-6.

10. Waitches GM, Stern EJ, Dubinsky TJ. Usefulness of the double-wall sign in detecting pneumothorax in patients with giant bullous emphysema. AJR Am J Roentgenol 2000;174:1765-8. 